\title{
Editorial: Geotechnical Innovation for Transport Infrastructures
}

\author{
Sanjay Nimbalkar ${ }^{1 *}$, Prabir K. Kolay ${ }^{2}$ and Yifei Sun ${ }^{3,4}$ \\ ${ }^{1}$ School of Civil and Environmental Engineering, University of Technology Sydney, Sydney, NSW, Australia, ${ }^{2}$ Department of \\ Civil and Environmental Engineering, Southern Illinois University, Carbondale, IL, United States, ${ }^{3}$ Key Laboratory of Ministry of \\ Education for Geomechanics and Embankment Engineering, Hohai University, Nanjing, China, ${ }^{4}$ Faculty of Civil and \\ Environmental Engineering, Ruhr University Bochum, Bochum, Germany
}

Keywords: geotechnical engineering, ground improvement, transportation infrastructures, road, railway

\section{Editorial on the Research Topic}

\section{Geotechnical Innovation for Transport Infrastructures}

\section{BACKGROUND}

The transportation and transit systems are crucial parts of a nation's economy playing major roles in efficiently managing the conveyance for passengers, mail, or freight. However, the service life performance of these systems is impeded by deterioration of key components including road/rail, base, and subgrade due to ever-growing traffic. Providing safe, efficient, and sustainable transport infrastructure is often challenging owing to complex geotechnical aspects of the ground. This Research Topic is designed to accommodate the interests of engineers and researchers in modeling and designing both geomaterials and geostructures that could improve performance, sustainability, and life cycle of transportation infrastructures. The topic involves a wide coverage of timely issues on technologies and innovations focusing on broad aspects of geotechnical innovations in order to address global grand challenges and UN's sustainable development goals with great social and economic importance. We are proud to present this topic containing 10 peer-reviewed contributions providing insights into geotechnical innovations crucial for sustainable transport in many continents, including Asia, Australia, Europe, and North America.

\section{MAJOR HIGHLIGHTS OF CONTRIBUTIONS}

Pile foundations supporting high-rise buildings and transport infrastructures are often subjected to eccentric lateral cyclic load arising from the action of wind, waves, high speed traffic, ship impacts etc. Such lateral load can induce torsion in pile and lead to progressive degradation of the soil strength and the axial pile capacity as reported through boundary element modeling (BEM) approach by Nimbalkar et al.. The results from this study can be utilized for formulating the design criteria for pile subjected to axial and torsional cyclic loads relevant to transport environment.

The granular soils including ballast usually experience dynamic loads in the field. The existing models are complex and can mainly be used to predict the monotonic stress-strain response of granular soils. However, the cyclic fractional constitutive model developed by $\mathrm{Li}$ et al. is simple and is able to capture the cyclic (repetitive) loading representative of traffic. By employing the discrete element modeling (DEM) approach in PFC 3D, Dahal and Mishra highlighted the significance of particle breakage in permanent deformation accumulation of ballast layer under cyclic loading. The gravel loss is a major limitation for unsealed roads and effects of three significant factors, material properties, traffic, 
and weather condition are assessed through extensive field investigations by Pardeshi et al.. Such gravel loss can be reduced by promoting the use of modified gravel than conventionally used material.

Hou et al. determined the material properties of aggregate quarry by-products through laboratory testing and materials characterization, and evaluated the feasibility of their use in various pavement applications. The study promotes the potential use of these materials with fly ash stabilization as sustainable pavement construction strategies. The laboratory study by Tripathi et al. evaluates the liquefaction characteristics of 2030 Ottawa sand with various percentages of monofilament polypropylene fibers through a series of stress-controlled cyclic triaxial tests. Test findings revealed a significant improvement in liquefaction resistance when the polypropylene fiber content exceeded beyond $0.075 \%$ at $34.47 \mathrm{kPa}$ effective confining stress. In the case of earthquake, bearing capacity assessment of a strip footing placed over an embankment of anisotropic clay is crucial as demonstrated by Krishnan et al.. The adoption of finite element limit analysis (FELA) approach combined with second-order conic optimization technique can enable correct assessment of such a strip footing used for various infrastructure projects including bridge abutments, roadways, and railways on flood plains or riverbanks.

The selection of a wide variety of subgrades, geogrid characteristics and placement locations in the study by Jiang and Nimbalkar have enabled the comprehensive assessment of geogrid-reinforced railroad under monotonic and cyclic loads. The results of finite element modeling (FEM) study in PLAXIS $2 \mathrm{D}$ reveals the more prominent role of geogrid for railroad located over the poor quality subgrade. The correct placement of geogrid at the ballast-sub-ballast interface as well as increasing the number of geogrids are found to bear favorable implications on track stability. The inclusion of $3 \mathrm{D}$ geoinclusion such as geocell in comparison with planar geogrid is found attractive in mitigation of traffic induced vibrations through finite difference modeling approach in FLAC 3D (Hegde and Venkateswarlu). The efficacy of geocell is more when it is placed at the shallow depth. Sun has investigated the potential use of recycled rubber tires for railroad using a 3D FEM implemented in ABAQUS. The rubber tire is found to radially confine the infilled materials effectively, and thus reduce excessive lateral spreading and vertical displacement.

\section{SUMMARY}

The salient contributions amply demonstrate the useful innovations in the area of geotechnical engineering, constitutive, and numerical modeling as well as ground improvement relevant to transportation infrastructures around the globe. We, editors, hope that you enjoy reading these articles and the Research Topic, as a whole.

\section{AUTHOR CONTRIBUTIONS}

SN prepared the draft. PK and YS edited the draft.

Conflict of Interest: The authors declare that the research was conducted in the absence of any commercial or financial relationships that could be construed as a potential conflict of interest.

Copyright (C) 2020 Nimbalkar, Kolay and Sun. This is an open-access article distributed under the terms of the Creative Commons Attribution License (CC BY). The use, distribution or reproduction in other forums is permitted, provided the original author(s) and the copyright owner(s) are credited and that the original publication in this journal is cited, in accordance with accepted academic practice. No use, distribution or reproduction is permitted which does not comply with these terms. 